\title{
Prevalence of HPV Genotypes in Adult Male Patients with Cutaneous Warts: A Cross-Sectional Study
}

\author{
Rana Al-Awadhi ${ }^{a} \quad$ Nawaf Al-Mutairi ${ }^{b}$ Wassim Chehadeh ${ }^{c}$ \\ ${ }^{a}$ Department of Medical Laboratory Sciences, Faculty of Allied Health Sciences, Kuwait University, Sulaibikhat, \\ Kuwait; ${ }^{b}$ Dermatology Unit, Department of Medicine, Faculty of Medicine, Kuwait University, Kuwait City, Kuwait; \\ 'Virology Unit, Department of Microbiology, Faculty of Medicine, Kuwait University, Kuwait City, Kuwait
}

\section{Significance of the Study}

- Nine human papillomavirus (HPV) types were detected in body warts taken from adult male patients.

- Five were from the a genus (HPV2, 6, 27b, 57b, 57c, and 94), 2 from the $\gamma$ genus (HPV4 and 65), and HPVla was from the mu genus.

- Single HPV infection was found in $93.4 \%$ of the patients (HPV27b was the most common type), whereas multiple infections were encountered in $6.6 \%$ (HPVla was the most common type, followed by HPV27b).

\section{Keywords}

Cutaneous warts · Human papillomavirus infection

\begin{abstract}
Aim: This study was aimed at determining the distribution of type-specific human papillomavirus (HPV) in men with cutaneous warts and correlating this with the clinical and morphological presentation of warts. Methods: Cutaneous wart samples were obtained from 167 adult men presenting to a dermatology clinic. The tissues were fixed and screened for HPV DNA using real-time PCR. The HPV genotype was determined by PCR-based sequencing. Results: Nine different HPV genotypes were detected, comprising 6 from the a genus (HPV2, 6, 27b, 57b, 57c, and 94), 2 from the $y$ genus (HPV4 and 65), and HPV1 a from the mu genus. Single HPV infection was encountered in $93.4 \%$ of the patients, whereas multiple infections were encountered in only $6.6 \%$. The prevalence of
\end{abstract}

\begin{tabular}{ll}
\hline karger@karger.com & $\begin{array}{l}\text { C) } 2020 \text { The Author(s) } \\
\text { Published by S. Karger AG, Basel }\end{array}$ \\
www.karger.com/mpp & This is an Open Access article licensed under the Creative Commons \\
Karger & $\begin{array}{l}\text { Attribution-NonCommercial-4.0 International License (CC BY-NC) } \\
\text { (http://www.karger.com/Services/OpenAccessLicense), applicable to } \\
\text { the online version of the article only. Usage and distribution for com- } \\
\text { mercial purposes requires written permission. }\end{array}$
\end{tabular}

HPV27b was highest among four body sites, followed by HPV57c, 1a, and 2. HPV1a was the most common genotype encountered in multiple infections, followed by HPV27b. Patient age, the number of warts, the duration of the presence of warts, and contact with people who have warts were not predictors of wart location. However, a high number of patients with palmar or common body warts had wart sizes of $<1 \mathrm{~cm}$. Conclusions: This study shows that genus a HPV types are detected in about $82 \%$ of patients with cutaneous warts.

(C) 2020 The Author(s)

Published by S. Karger AG, Basel

\section{Introduction}

Human papillomaviruses (HPVs) are among the most common infectious agents in humans, and they have a wide variety of cutaneous manifestations from benign 
proliferative warts to malignant carcinomas [1]. The classification of warts into mucosal and cutaneous types depends mainly on their morphological features and anatomical localization [1]. HPVs are associated with a variety of cutaneous manifestations, including common warts (verrucae vulgaris), plantar warts, plane warts (verrucae plana), anogenital warts, and those associated with epidermodysplasia verruciformis [2].

In common warts, or verrucae vulgaris, HPV1, 2, 4, and 7 are the most commonly associated genotypes [3]. These warts are prevalent in $3.5 \%$ of adults and $33 \%$ of children [4]. Most of them (95\%) are found on the hands, fingers, elbows, knees, and face [5]. In plantar warts, HPV1 is the most commonly associated genotype. Other genotypes have been documented, including HPV4, 57, $60,63,65$, and 66 [6]. These warts are common among children and are mostly located on the sole of the foot [3]. Plane warts are also common among children and are located on the face, dorsum of the hands, and shins [7]. HPV 3 and 10 are most commonly associated with plane warts. HPV types 26-29 and 41 have also been reported but with lower frequency [3]. Verrucae are spread by direct skin-to-skin contact or indirectly via contact with contaminated surfaces (e.g., in swimming pools or communal showers) [8]. Having a family member with a wart has been shown to be a stronger risk factor for infection of children than the use of swimming pools and shared bathing areas [4]. A laboratory diagnosis of skin warts is usually not necessary as they can be distinguished morphologically [9].

Treatments (chemical, physical, or immunological) are lengthy and expensive, cause inconvenience, and are often painful. Recurrence is frequent because of the persistence of HPV in perilesional skin [10]. Data on the distribution of HPV genotypes in cutaneous warts from the Middle East are limited. This study was therefore undertaken to determine the prevalence of the most common HPV types among adult male patients with cutaneous warts at different body locations.

\section{Subjects and Methods}

\section{Study Design and Participants}

This was a cross-sectional study on a nonprobabilistic sample. One hundred and sixty-seven male patients presenting to dermatology clinics in the Farwaniya Health District Area were recruited consecutively from November 2016 to May 2017. Adult males (median age 35 years, range 18-66) and immunocompetent patients with a previous clinical diagnosis of cutaneous warts scheduled for cryotherapy or laser treatment consented to participate in this study after a verbal explanation by the dermatologist. At the time of sampling, wart specimens were collected in universal transporting medium (HealthLink Inc., Copan Italia S.p.A., Brescia, Italy) and stored at $-80^{\circ} \mathrm{C}$.

Demographic and clinical information was obtained from each patient, including his age (years), the number of warts (1 vs. $2-4$ vs. $\geq 5$ ), the duration of the presence of warts ( $<6 \mathrm{vs.} \geq 6$ months), the size of each wart ( $<1$ vs. $1-2$ vs. $>2 \mathrm{~cm}$ ), whether the warts were subjected to prior treatment (yes vs. no), whether any family member had warts (yes vs. no), whether there was any contact with people who had warts (yes vs. no), and whether the wart caused any inconvenience (yes vs. no).

\section{DNA Extraction}

Tissue samples were stored at $-80^{\circ} \mathrm{C}$. Due to the large number of samples received, all warts from a given patient were minced together and were subjected to DNA isolation. The tissue was minced with sterile scissors and forceps on a Petri dish. About 25 $\mathrm{mg}$ of tissue was weighed and then washed in PBS and transferred into 1.5-mL Eppendorf tubes. Genomic DNA was extracted from the tissue samples using a QIAmp DNA Mini Kit (Qiagen, USA) according to the manufacturer's instructions. HPV type 2 and 1 vectors (American Type Culture Collection, Manassas, VA, USA) were used as controls in the PCR experiments.

\section{Real-Time PCR}

A real-time PCR assay was carried out to screen for HPV DNA in the cutaneous warts. Five microliters of extracted DNA was combined with $12.5 \mu \mathrm{L}$ of $2 \times$ SYBR Green master mix (Applied Biosystems, Foster City, CA, USA) containing ROX as a passive reference, and $10 \mathrm{pmol}$ of forward and reverse primers $(10 \mu \mathrm{M}$, described below). All sets of primers were custom synthesized by Thermo Fisher Scientific (Waltham, MA, USA). The mixture was made up to a $25-\mu \mathrm{L}$ volume with nuclease-free water (Ambion, Austin, TX, USA). The samples were analyzed in duplicate on an optical 96-well reaction plate (Applied Biosystems). Positive and negative controls were included in each amplification batch.

The real-time PCR assay was carried out on two different plates. The first plate was used to determine the integrity of the target DNA by $\beta$-globin PCR assay, amplifying a target of a 268 -bp fragment, as described previously by Lum and Le Marchand [11]. The nucleotide sequence of the $\beta$-globin primers was as follows: $\beta$-globin forward PCR primer, $5^{\prime}$-TGG GTT TCT GAT AGG CAC TGA CT- $3^{\prime}$; $\beta$-globin reverse PCR primer, $5^{\prime}$-AAC AGC ATC AGG AGT GGA CAG AT- $3^{\prime}$. PCR amplification was initiated at $95^{\circ} \mathrm{C}$ for $10 \mathrm{~min}$ and completed by 45 amplification cycles (denaturation at $95^{\circ} \mathrm{C}$ for $15 \mathrm{~s}$, annealing at $55^{\circ} \mathrm{C}$ for $45 \mathrm{~s}$, and extension at $65^{\circ} \mathrm{C}$ for $1 \mathrm{~min}$ ).

The second plate was used to screen for the presence of HPV infection using HVP2/B5 primers from HPV L1 ORF [12]. The nucleotide sequences of HVP2/B5 primers were as follows: HVP2 forward primer, 5' -TCN MGN GGN CAN CCN YTN GG-3'; B5 reverse primer, $5^{\prime}$-AYN CCR TTR TTR TGN CCY TG- $3^{\prime}$. The expected size of the amplified fragment was $650 \mathrm{bp}$. PCR amplification was initiated at $95^{\circ} \mathrm{C}$ for $10 \mathrm{~min}$ and completed by 45 amplification cycles (denaturation at $95^{\circ} \mathrm{C}$ for $15 \mathrm{~s}$, annealing at $50^{\circ} \mathrm{C}$ for $45 \mathrm{~s}$, and extension at $65^{\circ} \mathrm{C}$ for $1 \mathrm{~min}$ ).

Fluorescence spectra were recorded during the elongation phase of each PCR cycle. Sequence Detection Software (SDS version 1.7) of ABI 7500 real-time PCR was used to generate the amplification curve for each reaction. A dissociation curve was gener- 
Table 1. Clinical and morphological characteristics of the cutaneous warts in the adult males $(n=167)$

\begin{tabular}{|c|c|c|c|c|c|c|}
\hline Characteristic & $\begin{array}{l}\text { Plantar } \\
\text { warts only } \\
(n=97 ; 58.0 \%)\end{array}$ & $\begin{array}{l}\text { Palmar } \\
\text { warts only } \\
(n=29 ; 17.4 \%)\end{array}$ & $\begin{array}{l}\text { Plantar and } \\
\text { palmar warts } \\
(n=12 ; 7.2 \%)\end{array}$ & $\begin{array}{l}\text { Common } \\
\text { body warts }{ }^{1} \\
(n=29 ; 17.4 \%)\end{array}$ & $\begin{array}{l}\text { Total } \\
(n=167 ; 100 \%)\end{array}$ & $p$ value \\
\hline \multicolumn{7}{|l|}{ Patient age, years } \\
\hline Mean \pm SD & $35.8 \pm 11.1$ & $34.5 \pm 11.9$ & $39.4 \pm 9.3$ & $35.1 \pm 8.7$ & $35.3 \pm 11.2$ & 0.681 \\
\hline Median (range) & $35(18-66)$ & $31(18-61)$ & $39(23-50)$ & $34(23-54)$ & $35(18-66)$ & \\
\hline \multicolumn{7}{|l|}{ Number of warts } \\
\hline $2-4$ & $40(41.2)$ & $14(48.3)$ & $4(33.3)$ & $7(24.1)$ & $65(38.9)$ & \\
\hline$\geq 5$ & $41(42.3)$ & $7(24.1)$ & $8(66.7)$ & $16(55.2)$ & $72(43.1)$ & \\
\hline \multicolumn{7}{|c|}{ Duration of the presence of each wart } \\
\hline$<6$ months & $57(58.8)$ & $17(58.6)$ & $9(75.0)$ & $22(75.9)$ & $105(62.9)$ & 0.286 \\
\hline$\geq 6$ months & $40(41.2)$ & $12(41.3)$ & $3(25.0)$ & $7(24.1)$ & $62(37.1)$ & \\
\hline \multicolumn{7}{|l|}{ Size of each wart } \\
\hline Yes & $37(38.1)$ & $6(20.7)$ & $3(25.0)$ & $7(24.1)$ & $53(31.7)$ & 0.213 \\
\hline No & $60(61.9)$ & $23(79.3)$ & $9(75.0)$ & $22(75.9)$ & $114(68.3)$ & \\
\hline \multicolumn{7}{|c|}{ Family member has warts } \\
\hline Yes & $16(17.5)$ & $2(6.9)$ & $0(0)$ & $7(24.1)$ & $25(15.0)$ & 0.127 \\
\hline No & $80(82.5)$ & $27(93.1)$ & $12(100)$ & $22(75.9)$ & $142(85.0)$ & \\
\hline \multicolumn{7}{|c|}{$\begin{array}{l}\text { Contact with people who have warts, i.e., } \\
\text { at school or the gymnasium }\end{array}$} \\
\hline Yes & $4(4.1)$ & $2(6.9)$ & $0(0)$ & $0(0)$ & $6(3.6)$ & 0.472 \\
\hline No & $93(95.9)$ & $27(93.1)$ & $12(100)$ & $29(100)$ & $161(96.4)$ & \\
\hline \multicolumn{7}{|c|}{ Wart causes inconvenience ${ }^{2}$} \\
\hline Yes & $93(95.9)$ & $27(93.1)$ & $10(83.3)$ & $29(100)$ & $157(94.0)$ & 0.136 \\
\hline No & $4(4.1)$ & $2(6.9)$ & $2(16.7)$ & $0(0)$ & $10(6.0)$ & \\
\hline
\end{tabular}

Data are numbers of patients (\%) unless specified otherwise. SD, standard deviation. ${ }^{1}$ Obtained from the following body sites: face, beard, scalp, back, legs, arms, forearms, and trunk. ${ }^{2}$ Pain, irritation, or cosmetic inconvenience.

ated after each reaction to differentiate between specific and nonspecific amplicons. On the basis of the amplification curve, all samples with HPV amplification, starting at any cycle and up to cycle number 40 (with a cutoff line of 0.2 ) were selected for the analysis. Only samples with a dissociation curve between 70 and $80^{\circ} \mathrm{C}$, and a derivative value between 0.100 and 0.500 , were considered HPV DNA positive.

\section{Sanger Sequencing}

HPV DNA in warts was amplified by nested PCR prior to sequencing, using the AmpliTaq Gold Master Mix (Applied Biosystems). HVP2/B5 primers were used in the first PCR, and CN1F/ $\mathrm{CN} 1 \mathrm{R}, \mathrm{CN} 2 \mathrm{~F} / \mathrm{CN} 2 \mathrm{R}, \mathrm{CN} 3 \mathrm{~F} / \mathrm{CN} 3 \mathrm{R}$, and $\mathrm{C} 4 \mathrm{~F} / \mathrm{C} 4 \mathrm{R}$ primers in the second PCR [12].

The first PCR amplification was initiated at $95^{\circ} \mathrm{C}$ for $10 \mathrm{~min}$ and completed by 35 amplification cycles (denaturation at $95^{\circ} \mathrm{C}$ for $15 \mathrm{~s}$, annealing at $50^{\circ} \mathrm{C}$ for $45 \mathrm{~s}$, and extension at $68^{\circ} \mathrm{C}$ for 1 $\min$ ). The second PCR amplification was carried out using $3 \mu \mathrm{L}$ of the first PCR product and the same cycling conditions. The expected broad-spectrum HPV genotypes to be detected from cuta- neous warts using the HVP2/B5 and CN1F/CN1R, CN2F/CN2R, $\mathrm{CN} 3 \mathrm{~F} / \mathrm{CN} 3 \mathrm{R}$, and $\mathrm{C} 4 \mathrm{~F} / \mathrm{C} 4 \mathrm{R}$ primers included HPV types from the a genus (HPV2, 3, 6, 7, 10, 27, 28, 29, 40, 43, 57, 77, 91, and 94), the $\gamma$ genus (HPV4, 48, 50, 60, 65, 88, and 95), the mu genus (HPV1 and 63), and the nu genus (HPV41) [13].

The PCR products were purified using a PCR purification kit (NucleoSpin Extract II PCR Purification Kit; Macherey-Nagel GmbH \& Co. KG, Düren, Germany) as per the manufacturer's instruction. They were then subjected to Sanger sequencing reaction using BigDye Terminator version 3.1 Cycle Sequencing Mix (Applied Biosystems) and the nested PCR primers described above. Post-sequencing PCR purifications were performed to remove unbound fluorescent dye deoxy terminators using the BigDye XTerminator ${ }^{\mathrm{TM}}$ Purification Kit (Applied Biosystems). The samples were denatured for $2 \mathrm{~min}$ at $95^{\circ} \mathrm{C}$, immediately chilled on ice, and loaded on an ABI 3100 Genetic Analyzer (Applied Biosystems). The samples were electrophoresed on a $50-\mathrm{cm}$ capillary array using POP-6 polymer (Applied Biosystems) as a separation medium.

The samples were analyzed using Sequencing Analysis software version 3.7 (Applied Biosystems). HPV sequence alignment was 
Table 2. HPV type-specific prevalence among the male patients with cutaneous warts $(n=167)$

\begin{tabular}{llllll}
\hline HPV type & $\begin{array}{l}\text { Patients with } \\
\text { plantar warts } \\
(n=97)\end{array}$ & $\begin{array}{l}\text { Patients with } \\
\text { palmar warts } \\
(n=29)\end{array}$ & $\begin{array}{l}\text { Patients with } \\
\text { plantar and palmar } \\
\text { warts }(n=12)\end{array}$ & $\begin{array}{l}\text { Patients with } \\
\text { common body } \\
\text { warts }^{1}(n=29)\end{array}$ & $\begin{array}{l}\text { Total } \\
(n=167)\end{array}$ \\
\hline $27 \mathrm{~b}$ & $45(46.4)$ & $9(31.0)$ & $5(41.8)$ & $19(65.5)$ & $78(46.7)$ \\
$57 \mathrm{c}$ & $25(25.8)$ & $10(34.7)$ & $2(16.7)$ & $2(24.1)$ & $44(26.3)$ \\
$1 \mathrm{a}$ & $13(13.4)$ & $1(3.4)$ & 0 & 0 & $16(9.6)$ \\
2 & $9(9.3)$ & $3(10.5)$ & $1(8.3)$ & 0 & $13(7.8)$ \\
65 & $2(2.0)$ & $1(3.4)$ & 0 & 0 & $3(1.8)$ \\
$57 \mathrm{~b}$ & 0 & 0 & $1(8.3)$ & 0 & $1(0.6)$ \\
94 & 0 & $1(3.4)$ & 0 & 0 & $5(3.6)$ \\
$1 \mathrm{a}+27 \mathrm{~b}$ & $3(3.1)$ & $1(3.4)$ & $1(8.3)$ & 0 & $2(1.2)$ \\
$1 \mathrm{a}+57 \mathrm{c}$ & 0 & $1(3.4)$ & $1(8.3)$ & 0 & $1(0.6)$ \\
$1 \mathrm{a}+2$ & 0 & 0 & $1(8.3)$ & 0 & $1(0.6)$ \\
$1 \mathrm{a}+65$ & 0 & $1(3.4)$ & 0 & $1(3.4)$ & $1(0.6)$ \\
$6+27 \mathrm{~b}$ & 0 & 0 & 0 & 0 & $1(0.6)$ \\
$1 \mathrm{a}+2+4$ & 0 & $1(3.4)$ & 0 & & 2 \\
\hline
\end{tabular}

Data are numbers of patients (\%). Listed are all HPV types, including HPV2, 27b, 57b, 57c, and 94 from the a genus, HPV4 and 65 from the $\gamma$ genus, HPV6 from the $\beta$ genus, and HPV1a from the mu genus. HPV, human papillomavirus. ${ }^{1}$ Obtained from the following body sites: face, beard, scalp, back, legs, arms, forearms, and trunk.

performed with sequences presented in the GenBank database using BLASTn software (https://blast.ncbi.nlm.nih.gov/) and the Los Alamos Data National Laboratory Theoretical Biology and Biophysics HPV database (https://pave.niaid.nih.gov/).

\section{Statistical Analysis}

Data management, analysis, and graphical presentation were carried out using the Statistical Package for the Social Sciences (SPSS) computer software version 25.0 (IBM Corp., Armonk, NY, USA). The descriptive statistics are presented as number and percentage for categorical variables. The $\chi^{2}$ or Fisher's exact test was applied to find any association or significant differences between four cutaneous wart categories. All tests were two-tailed and a $p$ value $<0.05$ was considered statistically significant.

\section{Results}

Cutaneous warts taken from 167 male patients presenting to dermatology clinics were included in the study. The overall mean age of the patients was 35 years (Table 1). The results show that $58 \%$ of the patients had plantar warts, whereas $17.4 \%$ had palmar warts, $17.4 \%$ had common body warts, and the rest (7.2\%) had palmar and plantar warts. The overall median number of warts was 4 , ranging between 1 and 25, and almost $43 \%$ of the patients had $\geq 5$ warts. Almost $63 \%$ of the patients were found to have had warts for $<6$ months. More than half (54.5\%) of the warts were $\leq 1 \mathrm{~cm}$, while the difference in size of the warts between the four groups of patients was statistically significant $(p=0.008)$. As such, $~ 57 \%$ of the patients with plantar warts and $\sim 66 \%$ of those with common body warts had warts sized $<1 \mathrm{~cm}$, whereas $52 \%$ of the patients with palmar warts and $50 \%$ of those with plantar and palmar warts had warts between 1 and $2 \mathrm{~cm}$ in size. Of note, $68.3 \%$ of the patients denied having had prior treatment, and $85 \%$ denied having a family member with warts. Almost all (96.4\%) denied having had previous contact with people who had warts. The warts caused inconvenience in $94 \%$ of the patients. Patient age, the number of warts, the duration of the presence of warts, and contact with people who have warts were not predictors of wart location.

The analysis of the sequencing results showed that there were 9 different HPV genotypes detected in this study, including HPV genotypes $1 \mathrm{a}, 2$, 4, 6, 27b, 57b, 57c, 65 , and 94. Table 2 presents the prevalence of HPV genotypes according to the location of the warts and whether the patient was infected with one, two, or three HPV types. Single HPV infection was encountered in $93.4 \%$ of the patients, whereas multiple infections were encountered in $6.6 \%$. The HPV27b genotype was the most common among the four body sites, followed by HPV 57c, 1a, and 2. The prevalence of the four most common HPV genotypes was $90.4 \%$. HPV genotype 1a was the most common genotype encountered in multiple HPV infections. 
Table 3. Comparison of the clinical characteristics of plantar $(n=70)$ and palmar warts $(n=19)$ between HPV27b and HPV57c infections

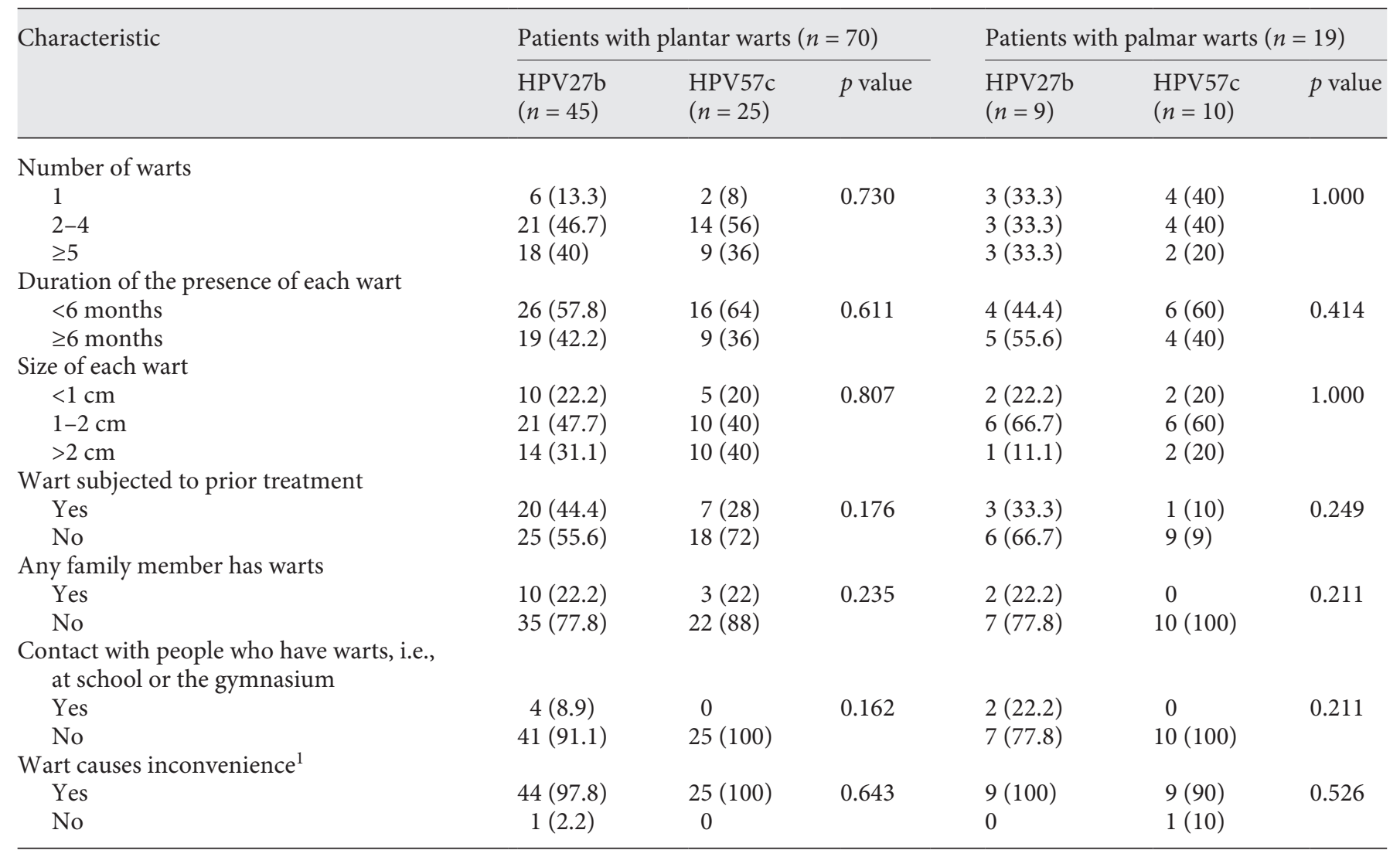

Data are numbers of patients (\%). HPV, human papillomavirus. ${ }^{1}$ Pain, irritation, or cosmetic inconvenience.

Table 3 compares the characteristics of HPV27b-infected cutaneous warts with those of warts infected with HPV57c at palmar and plantar locations. The analysis of the results showed that the majority of the plantar warts infected with HPV27b and HPV57c exhibited almost the same characteristics as all 167 wart samples. There was no statistically significant difference in clinical characteristics between the two HPV types.

\section{Discussion}

This study aimed to investigate the relationship between the type-specific distribution of HPV genotypes and the clinical characteristics of cutaneous warts in male patients. HPV27b was the most common type at almost all body sites. HPV57c, 1a, 2, and other types were also detected in this study. In multiple HPV infections, HPVla was the most common. This finding is in agree- ment with other studies [14-17] showing HPV2, 27, 57, and 1 as the most commonly detected HPV genotypes in plantar warts and other body sites.

Our analysis of the clinical characteristics of the warts revealed that regardless of the HPV type, the size of the wart was a significant feature of wart location. This feature was investigated by Hogendoorn et al. [18], who found that the mean size of warts in patients with plantar and common body warts was $4.9 \mathrm{~mm}$. In around $43 \%$ of our patients, warts were found in clusters of $\geq 5$, and they caused inconvenience to most patients. These findings are also in agreement with previously published studies [14, 19].

Another interesting finding was that a large number of patients had had warts for $<6$ months. Park et al. [19] and Bruggink et al. [14] showed that the majority of their patients had had warts for $\geq 6$ months, and Hogendoorn et al. [18] showed that the longer the warts had been present, the less likely HPV DNA was detected. Interestingly, there was no significant difference in the clinical and 
morphological presentation of warts between HPV27b and HPV57c infections, a finding that is in agreement with Hogendoorn et al. [18], who showed that more HPV27-infected warts were found in the plantar region. Our finding is also in agreement with Bruggink et al. [14], who showed that warts infected with HPV27 and warts infected with HPV57 had a similar clinical profile.

The importance of our study lies in the fact that it shows a relationship between the type-specific distribution of HPV genotypes and the clinical characteristics of cutaneous warts in male patients from the Middle East. A clinical characterization of other than morphological features of warts may be useful in planning treatment. The characteristics are well known $[20,21]$ and include the patient's age and the location, duration, and number of warts. The current study adds wart size to the above-mentioned prognostic features which could contribute to appropriate treatment.

\section{Conclusions}

This study shows that HPV27b and 57c were the most common types found in cutaneous warts taken from adult male patients. In a high number of patients, the warts were found in clusters of $\geq 5$, having an average size of $<2 \mathrm{~cm}$.

\section{Acknowledgements}

This work was funded by the Kuwait University Research Sector (Research Project No. NM 01/12). The authors are grateful to the staff of the Research Core Facility, Project No. SRUL 02/13, for their help and assistance.

\section{Statement of Ethics}

Ethical approval was obtained from the Ethics Committee of the Health Science Center, Kuwait University (No. VDR/EC/2310), and the Ministry of Public Health. Each patient was interviewed and consented to enter the study. The patients were asked to sign a consent form after a verbal explanation by the physician soliciting their participation. All study procedures were performed in compliance with the ethical standards of the revised Declaration of Helsinki of 2008 .

\section{Disclosure Statement}

The authors declare that they have no conflicts of interest.

\section{Funding Sources}

This work was funded by Kuwait University through the Research Administration (Research Project No. NM 01/12). The funder had no role in the study design, data collection and analysis, decision to publish, or preparation of the manuscript.

\section{Author Contributions}

R.A. was responsible for the design of the study, writing of the grant, monitoring the virology work, analysis of the results, and writing of the manuscript; N.M. was responsible for the collection of samples; W.C. was responsible for the virology work and writing of the manuscript.

\section{References}

1 Rübben A, Kalka K, Spelten B, GrussendorfConen EI. Clinical features and age distribution of patients with HPV 2/27/57-induced common warts. Arch Dermatol Res. 1997 May;289(6):337-40.

2 Stoler MH. Human papillomaviruses and cervical neoplasia: a model for carcinogenesis. Int J Gynecol Pathol. 2000 Jan;19(1):16-28.

3 Cardoso JC, Calonje E. Cutaneous manifestations of human papillomaviruses: a review. Acta Dermatovenerol Alp Pannonica Adriat. 2011 Sep;20(3):145-54.

4 van Haalen FM, Bruggink SC, Gussekloo J, Assendelft WJ, Eekhof JA. Warts in primary schoolchildren: prevalence and relation with environmental factors. Br J Dermatol. 2009 Jul;161(1):148-52.
5 Al-Mutairi N, AlKhalaf M. Mucocutaneous warts in children: clinical presentations, risk factors, and response to treatment. Acta Dermatovenerol Alp Pannonica Adriat. 2012 Dec;21(4):69-72.

6 Tschandl P, Rosendahl C, Kittler H. Cutaneous human papillomavirus infection: manifestations and diagnosis. Curr Probl Dermatol. 2014;45:92-7.

7 McLaughlin JS, Shafritz AB. Cutaneous warts. J Hand Surg Am. 2011 Feb;36(2):343-4.

8 Johnson LW. Communal showers and the risk of plantar warts. J Fam Pract. 1995 Feb; 40(2):136-8.

9 Swygart C. Human papillomavirus: disease and laboratory diagnosis. Br J Biomed Sci. 1997 Dec;54(4):299-303.
10 Aubin F, Guerrini JS. Clinical and benign aspects of human papillomavirus-associated lesions [in French]. Bull Acad Natl Med. 2007 Mar;191(3):585-97.

11 Lum A, Le Marchand L. A simple mouthwash method for obtaining genomic DNA in molecular epidemiological studies. Cancer Epidemiol Biomarkers Prev. 1998 Aug;7(8):71924.

12 Harwood CA, Spink PJ, Surentheran T, Leigh IM, de Villiers EM, McGregor JM, et al. Degenerate and nested PCR: a highly sensitive and specific method for detection of human papillomavirus infection in cutaneous warts. J Clin Microbiol. 1999 Nov;37(11):3545-55. 
13 de Koning MN, ter Schegget J, Eekhof JA, Kamp M, Kleter B, Gussekloo J, et al. Evaluation of a novel broad-spectrum PCR-multiplex genotyping assay for identification of cutaneous wart-associated human papillomavirus types. J Clin Microbiol. 2010 May;48(5): 1706-11.

14 Bruggink SC, de Koning MN, Gussekloo J, Egberts PF, Ter Schegget J, Feltkamp MC, et al. Cutaneous wart-associated HPV types: prevalence and relation with patient characteristics. J Clin Virol. 2012 Nov;55(3):250-5.

15 Köhler A, Meyer T, Stockfleth E, Nindl I. High viral load of human wart-associated papillomaviruses (PV) but not beta-PV in cutaneous warts independent of immunosuppression. Br J Dermatol. 2009 Sep;161(3): 528-35.
16 Sasagawa T, Mitsuishi T. Novel polymerase chain reaction method for detecting cutaneous human papillomavirus DNA. J Med Virol. 2012 Jan;84(1):138-44.

17 Al Bdour S, Akkash L, Shehabi AA. Detection and typing of common human papillomaviruses among Jordanian patients. J Med Virol. 2013 Jun;85(6):1058-62.

18 Hogendoorn GK, Bruggink SC, de Koning MN, Eekhof JA, Hermans KE, Rissmann R, et al. Morphological characteristics and human papillomavirus genotype predict the treatment response in cutaneous warts. Br J Dermatol. 2018 Jan;178(1):253-60.
19 Park SE, Ha JW, Kim CW, Kim SS. Preliminary study of analyzing mucosal human papillomaviruses in cutaneous warts by restriction fragment mass polymorphism. J Dermatol. 2017 Dec;44(12):1368-73.

20 Bruggink SC, Gussekloo J, Berger MY, Zaaijer K, Assendelft WJ, de Waal MW, et al. Cryotherapy with liquid nitrogen versus topical salicylic acid application for cutaneous warts in primary care: randomized controlled trial. CMAJ. 2010 Oct;182(15):1624-30.

21 Gibbs S, Harvey I. Topical treatments for cutaneous warts. Cochrane Database Syst Rev. $2006 \mathrm{Jul} ;(3): C D 001781$. 